\title{
El impacto de la secuencia visual en la comprensión simbólica de acciones en imágenes
}

\author{
The Impact of the Uisual Sequence on the Symbolic Understanding of Actions \\ on Images \\ 0 impacto da sequência visual na compreensão simbólica de ações em imagens
}

\author{
Daniela Jauck ${ }^{*}$ \\ Olga Peralta \\ IRICE-Conicet
}

Doi: https://doi.org/10.12804/revistas.urosario.edu.co/apl/a.7953

\begin{abstract}
Resumen
$\overline{\text { La comprensión simbólica de imágenes que representan }}$ acciones constituye un desafío cognitivo en edades tempranas. Esta investigación indaga por el impacto de la presentación de la secuencia visual de acciones dirigidas hacia un fin en la comprensión simbólica de las imágenes que las representan. Niños y niñas de 30 a 36 meses de edad fueron asignados a dos condiciones en las que se manipuló la presentación o no de una secuencia. Los niños y las niñas observaron por medio de una tableta imágenes de distintas acciones; luego, debían escoger un objeto real que mostraba el resultado de cada acción. Se encontró que la presencia de la secuencia constituyó un factor que potencia la comprensión de las imágenes como representaciones de acciones reales.

Palabras clave: secuencia; acciones; imágenes; comprensión simbólica temprana.
\end{abstract}

\begin{abstract}
flbstract
The symbolic understanding of images that represent actions constitutes a cognitive challenge at early ages. This research investigates the impact of the presentation of the visual sequence of goal-directed actions on the symbolic understanding of the images representing them. Thirty to thirty-six-months-old children were assigned to two conditions in which the presence or absence of the sequence was manipulated. Children observed images of different actions on a tablet; afterwards, they had to choose a real object that showed the result of each action. Results showed that the presence of the sequence constituted a factor that enhances the early understanding of images as representations of real actions.

Keywords: sequence; actions; images; early symbolic understanding.
\end{abstract}

\footnotetext{
ORCID ID: https://orcid.org/0000-0003-4599-5059

Dirigir correspondencia a Daniela Jauck. Instituto Rosario de Investigaciones en Ciencias de la Educación (IRICE) - Consejo Nacional de Investigaciones Científicas y Técnicas (CONICET), Boulevard 27 de Febrero 201 bis. Rosario, provincia de Santa Fe. Argentina. Correo electrónico: jauck@irice-conicet.gov.ar

Las autoras declaran no tener conflicto de intereses.
}

Para citar este artículo: Jauck, D., \& Peralta, O. (2020). El impacto de la secuencia visual en la compresión simbólica de acciones en imágenes. Avance en Psicología Latinoamericana, 38(2), 1-10. https://doi.org/10.12804/revistas.urosario.edu.co/apl/a.7953 


\section{Resumo}

A compreensão simbólica de imagens que representam ações constitui um desafio cognitivo em idades precoces. Esta pesquisa indaga o impacto da apresentação da sequência visual de ações dirigidas para um fim na compreensão simbólica das imagens que as representam. Crianças de 30 a 36 meses de idade foram designados a duas condições nas que se manipulara a apresentação ou não da uma sequência. As crianças observaram por meio de uma tablet imagens de distintas ações; depois, deviam escolher um objeto real que mostrava o resultado de cada ação. Encontrou-se que a presença da sequência constituiu um fator que potencia a compreensão das imagens como representações de ações reais.

Palavras-chave: sequência; ações; imagens; compreensão simbólica precoce.

En la actualidad nos encontramos diariamente con todo tipo de imágenes en libros, fotografías, etiquetas, carteles y en dispositivos digitales. Las imágenes provistas por computadoras y teléfonos celulares están muy presentes en la vida cotidiana y resultan muy atractivas para niños y niñas desde muy temprana edad. Es frecuente que ellos utilicen este tipo de imágenes para jugar, mostrando una gran destreza. Por ello, padres, madres, educadores y educadoras suelen asumir que los pequeños y las pequeñas comprenden la naturaleza simbólica de estas imágenes (e.g., Jauck \& Peralta, 2017; Rideout, 2017; Rideout \& Hamel, 2006; Vittrup et al., 2016; Waismana, Hidalgoa \& Rossia, 2018). Sin embargo, aunque lúdico y simbólico no son categorías excluyentes, jugar con las imágenes no necesariamente implica su comprensión y utilización como representaciones que refieren a la realidad (DeLoache, 1987; 2004; Ittelson, 1996; Sheenan \& Uttal, 2016).

Esta investigación surge de un estudio previo que indagó por la comprensión simbólica de secuencias de imágenes digitales que representan acciones por parte de niñas y niños de 24, 30 y 36 meses de edad
(Jauck \& Peralta, 2017). Los resultados mostraron que a $\operatorname{los} 30$ y 36 meses, pero no a los 24 , los niños y niñas comprendieron que las secuencias de imágenes referían a una acción que podía tener lugar en la realidad. Estos resultados concuerdan con diversas investigaciones que han mostrado que los niños $\mathrm{y}$ las niñas de esta edad comprenden las imágenes en sí mismas pero no las interpretan simbólicamente (Sigel, 1978; Troseth, 2003). La comprensión de la función de representación de las imágenes, como la de todo objeto simbólico, constituye un desafío cognitivo. Para entender y utilizar un objeto simbólico es necesario representarse en simultáneo tanto sus características concretas como su relación abstracta con lo que representa (DeLoache, 1987; 2004). Las pequeñas y los pequeños no muestran esta flexibilidad cognitiva, ven al símbolo como un objeto en sí mismo, lo que les dificulta ver en él a su referente (Ittelson, 1996).

En virtud de los resultados obtenidos por Jauck y Peralta (2017), en el estudio que aquí se presenta, trabajamos con niños y niñas de 30 a 36 meses de edad. Indagamos por el impacto de una variable que no había sido previamente investigada: la presencia o ausencia de la secuencia visual de las acciones en la comprensión simbólica de las imágenes que las representan. Este estudio se sitúa en una línea de investigación que conjuga dos vertientes que tradicionalmente se han abordado en forma separada: comprensión de acciones y comprensión simbólica de imágenes (Jauck \& Peralta, 2017; 2019).

Como ha sido documentado, desde muy pequeños los y las bebés comprenden secuencias de acciones realizadas por otros y las interpretan como dirigidas hacia un fin (Baldwin et al., 2008). Es decir, no ven solo movimientos en el espacio, sino movimientos organizados entre actores y metas (Woodward, 1998; Woodward \& Gerson, 2014). Por ejemplo, en un estudio clásico, Woodward (1998) familiarizó (mostrando reiteradamente) a bebés de 6 meses con imágenes de una escena en la que el brazo de una persona tomaba uno de dos 
juguetes: una pelota localizada en la parte superior de la imagen o un oso de peluche localizado en la parte inferior. Luego, los y las bebés veían nuevamente las imágenes, pero se introducía un cambio ya fuera en la trayectoria del movimiento del brazo o en la posición del objeto, el objeto que estaba arriba pasaba abajo o viceversa. Los resultados mostraron que los y las bebés se sorprendían (miraban más) cuando la persona cambiaba su objetivo, pero no cuando cambiaba la trayectoria del movimiento de su brazo. Estos resultados sugieren los y las bebes interpretan las acciones como dirigidas a metas, y no únicamente como movimientos en el espacio.

Baldwin et al. (2001), por su parte, encontraron que bebés de 11 meses extraen información de acciones en videos cuando las acciones ocurren de manera continua y en secuencias coincidentes con los límites de los objetivos e intenciones de un actor. También, Saylor et al. (2007) exploraron la segmentación de acciones reportando que a partir de los 9 meses los y las bebés responden a los límites de las acciones humanas. De acuerdo con estos estudios la comprensión de acciones se facilita cuando las mismas tienen lugar en forma continua o en secuencias coincidentes con los límites de las intenciones de un agente.

Las investigaciones revisadas aportan información importante sobre la comprensión de acciones, ya sea en vivo o en imágenes; sin embargo, estas no exploraron si los niños y las niñas toman las imágenes de forma simbólica, o sea, como representaciones de acciones reales.

Harris, Kavanaugh y Dowson (1997) llevaron a cabo una investigación que unió la comprensión de acciones con la comprensión simbólica de las imágenes que las representan. Estos autores indagaron por la utilización de una imagen para comunicar información acerca de acciones reales o imaginarias efectuadas sobre un objeto. En esta investigación un experimentador "hacía como si" o vertía una salsa sobre un juguete y luego pedía al niño o a la niña que seleccionara una fotografía (entre tres) que mostraba el resultado de la acción. Las y los menores de 28 meses seleccionaron al azar, pero los y las mayores escogieron la imagen que exhibía el resultado de la acción real, mostrando que no solo comprendieron la acción, sino que tomaron las imágenes de forma simbólica.

En cuanto a la comprensión simbólica de imágenes digitales representando acciones, Jauck y Peralta (2017) diseñaron una tarea en la que los niños y las niñas pequeños observaban acciones presentadas en secuencias de cuatro imágenes consecutivas, sin mostrar el resultado final. A continuación, se presentaban tres objetos reales y los niños y las niñas debían escoger el que exhibía el resultado de la acción (1- objeto con la modificación correcta, 2- objeto sin modificación, 3- objeto con otra modificación). Los resultados mostraron que los niños y las niñas de 30 y 36 meses comprendieron que las secuencias referían a una acción de la realidad, ya que escogieron el objeto que mostraba el resultado de la acción que había sido presentada en las imágenes. En suma, si bien y como ha sido ampliamente demostrado a los 24 meses de edad los niños comprenden acciones realizadas por otros y las interpretan como dirigidas hacia un fin, no acceden a la comprensión simbólica de imágenes, por lo que no las toman como representaciones de la realidad. En virtud de estos resultados, en la investigación que aquí se presenta trabajamos con niños y niñas de 30 y 36 meses de edad. Nos preguntamos por el impacto de la presencia de una secuencia visual en la comprensión simbólica de imágenes que representan acciones dirigidas hacia un fin.

\section{Método}

\section{Diseño}

Para la presente investigación se adaptó la metodología utilizada por Jauck y Peralta (2017). Se diseñaron dos condiciones experimentales según la presencia o ausencia de la secuencia de la acción en 
la presentación de las imágenes. Condición 1: Con Secuencia (CS) y Condición 2: Sin Secuencia (SS). En la condición CS se presentaron las acciones en secuencias de imágenes. En la condición ss, cada acción se mostró en una imagen.

\section{Participantes}

Treinta niños y niñas de 30 a 36 meses de edad ( $M=33.55 ; D T=3.12$ ) fueron asignados al azar en igual número a una de las condiciones. En la condición cs participaron 15 niños y niñas $(M=32.47 ; D T=3.27 ;$ Rango $=29-36), 8$ niñas y 7 niños, y en la condición ss participaron 15 niñas y niños $(M=34.27 ; D T=2.46$; Rango=30-36), 8 niñas y 7 niños.

Los participantes eran de nivel socioeconómico medio. Todos los padres y madres tenían escolaridad secundaria completa, algunos terciaria o universitaria, y se desempeñaban en sus profesiones o en actividades comerciales. Algunas madres trabajaban solo en el hogar. Los niños y niñas asistían a establecimientos educativos de gestión pública y privada localizados en una ciudad de tamaño mediano de la región central de Argentina. Tanto la composición de la matrícula como la educación que recibían los niños y las niñas en los establecimientos públicos y privados revestían características similares. Dada su corta edad, los niños y las niñas permanecían en los establecimientos alrededor de tres horas diarias. Las actividades educativas en ningún caso incluían el uso de tabletas. Según lo informado por padres y madres, los niños y las niñas no tenían acceso diario o frecuente a tabletas $\mathrm{u}$ otro tipo de computadoras con pantallas táctiles, pero sí a teléfonos celulares inteligentes (smartphones). Según los datos proporcionados por los adultos responsables y por el establecimiento educativo y personal a cargo, todos los participantes poseían un desarrollo esperado para su edad.

Primero se realizó una entrevista con los directivos en la que se presentó el proyecto y se explicaron los pasos a seguir en la toma de datos. Una vez que la institución dio su consentimiento para trabajar, se realizó una reunión con los padres, madres o adultos responsables de los niños y las niñas donde se explicó el proyecto de investigación y sus objetivos, a la vez que se aclararon todas las dudas que pudieran surgir. Luego, se enviaba una nota para obtener el consentimiento informado por escrito.

Respecto de los niños y las niñas, la experimentadora los invitaba a participar, si asentían se tomaba como su consentimiento a formar parte de la investigación, así solo se trabajó con aquellos niños que quisieron participar. A excepción de dos niños, todos aceptaron participar en forma muy entusiasta.

\section{Materiales}

Se utilizó una tableta de 10.1 " en la que se presentaban imágenes de acciones simples y cotidianas dirigidas hacia un fin: abrir o destapar, verter jugo, introducir una naranja en un recipiente, ensuciar un osito de juguete con pintura, romper un papel y cortar una manzana. Las imágenes presentaban acciones realizadas por una figura humana que no mostraba el rostro, solo el torso o los brazos y las manos con el propósito de que la atención se focalizase en la acción ejecutada sobre los objetos. Las imágenes mostraban la secuencia de la acción pero no el resultado. También se utilizaron los objetos reales (papeles, manzanas y osito de peluche) que mostraban opciones de elección de posibles resultados de las acciones presentadas en las imágenes: 1. Objeto con la modificación correcta, 2. Objeto sin modificación alguna, 3. Objeto con otra modificación. La tabla 1 muestra los materiales empleados.

\section{Procedimiento}

La experimentadora trabajó con cada niño o niña en forma individual en un aula de los establecimientos educativos especialmente destinada para 
Tabla 1. Imágenes y objetos como opciones de elección

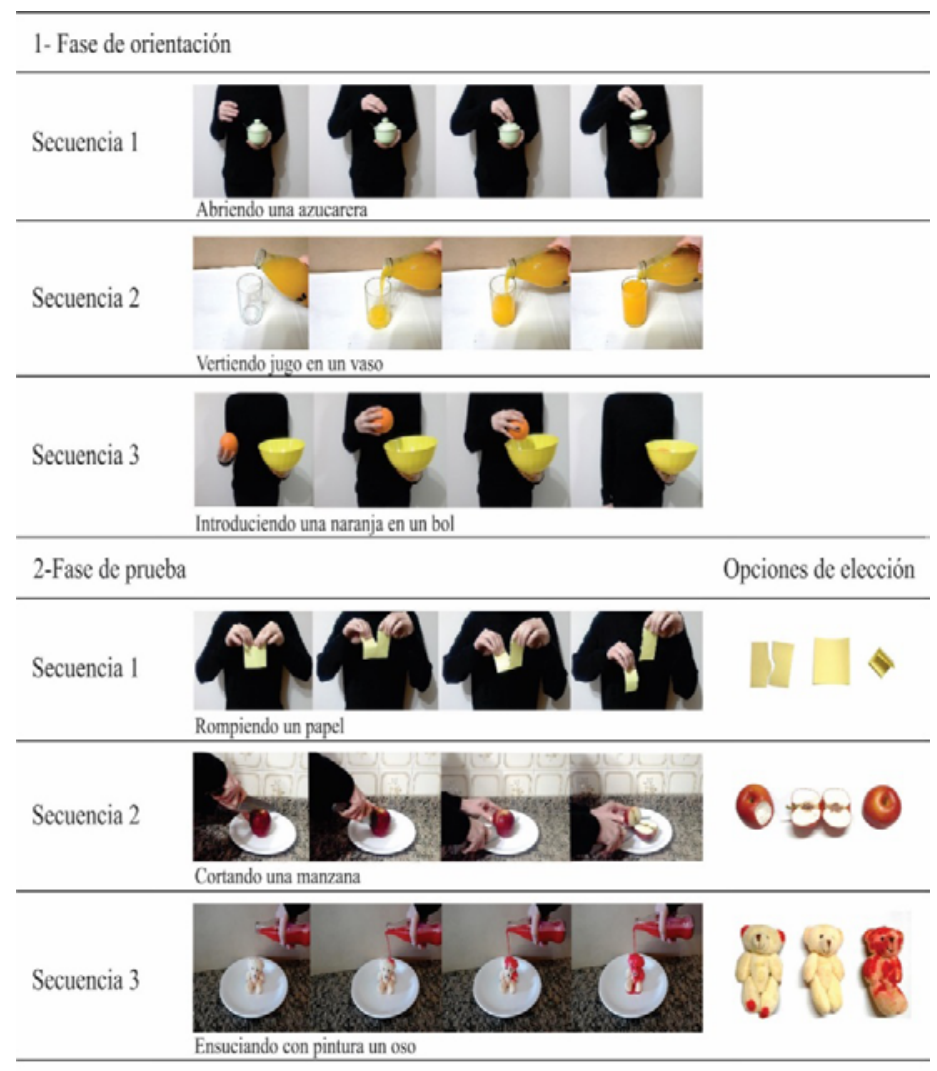

realizar la tarea. De esta manera, los niños y las niñas podían estar cómodos y no ser distraídos por otros niños, niñas o estímulos presentes en el aula. Cabe destacar que este ámbito resulta propicio y familiar para los niños, pues constituye una buena solución de compromiso entre la dificultad para el acceso a los hogares y la artificialidad de los laboratorios. La actividad completa duró entre 10 y 15 minutos.

Para comenzar, la experimentadora invitaba al niño o a la niña a sentarse en una mesa donde estuviera cómodo/a y pudiera observar las imágenes en la tableta. En una mesa contigua se encontraban los objetos reales (elecciones) ocultos bajo telas opacas.

El procedimiento de las dos condiciones constaba de dos fases: Orientación y Prueba. En ambas el orden de presentación de las subpruebas y elecciones fue contrabalanceado para neutralizar la probabilidad que un orden resultase más sencillo que otro o que se produjera un aprendizaje con un determinado orden, pero no con otro.

Las imágenes eran mostradas por la experimentadora mediante el deslizamiento del dedo índice en la pantalla. Una vez que los niños y las niñas observaron cada secuencia de cuatro imágenes o la cuarta imagen (según la condición), se les pedía que eligieran el resultado de la acción escogiendo una de tres opciones posibles: 1. Objeto con la modificación correcta, 2. Objeto sin modificación alguna, 3. Objeto con otra modificación. La tabla 2 ilustra el procedimiento empleado.

\section{Condición CS}

Orientación. Se introducía al niño o la niña en la tarea diciendo: "Te voy a mostrar unas fotos". Luego, la experimentadora le presentaba en la tableta cuatro secuencias de acciones; mientras pasaban 
las imágenes, preguntaba “¿Qué está haciendo?”. Al finalizar la presentación de cada secuencia, le decía el resultado de la acción (e.g., Secuencia 1: ¿Qué está haciendo? ¡Viste cómo abrió!). El propósito de esta fase era asegurarse de que el niño prestase atención a la acción representada.

Prueba. Esta fase constaba de tres subpruebas. Cada subprueba se conformó por una secuencia de cuatro imágenes. Se mostraban las secuencias en forma sucesiva y, en cada una de ellas, se preguntaba nuevamente: “QQué está haciendo?”, sin verbalizar el resultado de la acción. Inmediatamente después de presentar cada secuencia, se invitaba al niño o a la niña a elegir el objeto real que mostraba el resultado de la acción diciendo: “¿Me muestras cómo quedó?”.

Tabla 2. Procedimiento por condición experimental

\begin{tabular}{|c|c|c|c|}
\hline Condiciones & Procedimiento & Ejemplos & \\
\hline \multirow{4}{*}{ Con secuencia (CS) } & $\begin{array}{l}\text { Orientación: se presentan } \\
\text { acciones en una secuencia de } \\
\text { tres imágenes, al finalizar se } \\
\text { enuncia el resultado. }\end{array}$ & $\begin{array}{l}\text { Abrir } \\
\text { ¡Mira! ¿Qué está haciendo? }\end{array}$ & \\
\hline & & & \\
\hline & \multirow{2}{*}{$\begin{array}{l}\text { Prueba: se presentan en forma } \\
\text { sucesiva tres acciones en } \\
\text { secuencias y se pide al niño que } \\
\text { escoja el objeto real que muestra } \\
\text { el resultado de cada acción. }\end{array}$} & Ensuciar & Opciones de elección \\
\hline & & $\begin{array}{l}\text { ¿Me muestras cómo quedó? } \\
\text { ¿Me }\end{array}$ & $\Leftrightarrow$ is 8 \\
\hline \multirow{4}{*}{ Sin secuencia (SS) } & $\begin{array}{l}\text { Orientación: se presenta solo la } \\
\text { cuarta imagen. Al finalizar se } \\
\text { enuncia el resultado final. }\end{array}$ & $\begin{array}{l}\text { Abrir } \\
\text { ¡Mira! ¿Qué está haciendo? }\end{array}$ & \\
\hline & & ¡Viste cómo abrió! & \\
\hline & \multirow[b]{2}{*}{$\begin{array}{l}\text { Prueba: se presenta solo la } \\
\text { última imagen de cada acción } \\
\text { y se pide al niño que escoja } \\
\text { el objeto real que muestra el } \\
\text { resultado de la acción. }\end{array}$} & Ensuciar & Opciones de elección \\
\hline & & $\begin{array}{l}\text { ¿Mira! ¿Qué está haciendo? } \\
\text { ¿Me muestras cómo quedó? }\end{array}$ & $\Leftrightarrow$ is 8 \\
\hline
\end{tabular}

\section{Condición SS}

Los procedimientos seguidos en la condición SS eran los mismos a los de la condición anterior, la diferencia radicó en que en lugar de mostrar cuatro imágenes solo se presentaba una, la que correspondía a la imagen final de la secuencia.

\section{Estrategia de análisis}

El número de subpruebas correctas fue la variable dependiente sobre la que se efectuaron los análisis (se informan también porcentajes para una mayor claridad). Una respuesta fue considerada correcta si el niño o la niña señalaba o tocaba el 
objeto que mostraba el resultado de la acción. Se tuvo en cuenta solo la primera elección, cada participante podía tener una puntuación máxima de tres subpruebas correctas en la tarea.

Se efectuó un análisis no-paramétrico debido al tamaño de la muestra y a que no se asumió una distribución normal. Primero se analizó la ejecución de los y las participantes dentro de cada condición contra el azar, utilizando la prueba binomial con el objetivo de evaluar si las respuestas superaban o no la probabilidad de acierto por azar. Luego se comparó la ejecución entre condiciones mediante la prueba U Mann-Whitney. Adicionalmente, se analizó el desempeño individual con base en el criterio de sujeto exitoso. Un/a participante fue considerado exitoso/a si respondía correctamente a las tres subpruebas.

\section{Resultados}

Los análisis en cuanto a la ejecución por azar mostraron que la ejecución fue superior a lo esperable por azar en la condición CS, en la que se proveyó de la secuencia de las acciones en cuatro imágenes. Sobre un total de 45 respuestas, esta condición alcanzó un total de 41 respuestas correctas $(91 \%)$, lo cual supera la probabilidad de elegir al azar, testada a través de la prueba binomial $(p<.0001)$. En la condición ss, en la que solo se mostró la última imagen, la ejecución también superó los niveles de azar con 27 de 45 respuestas correctas $(60 \%)$, prueba binomial $(p<.0001)$. Estos resultados indican que la ausencia de la secuencia afectó, aunque no significativamente, la ejecución de los niños y las niñas en cada condición.

La comparación entre condiciones mostró que la ejecución fue significativamente superior en la tarea CS, 41 (91\%) respuestas correctas frente a 27 $(60 \%)$ de la condición SS $(U=42.50 ; p<0.002)$. Estos resultados muestran nuevamente el potente efecto de la presencia de la secuencia en la com- prensión simbólica de las imágenes que representan una acción real (figura 1).

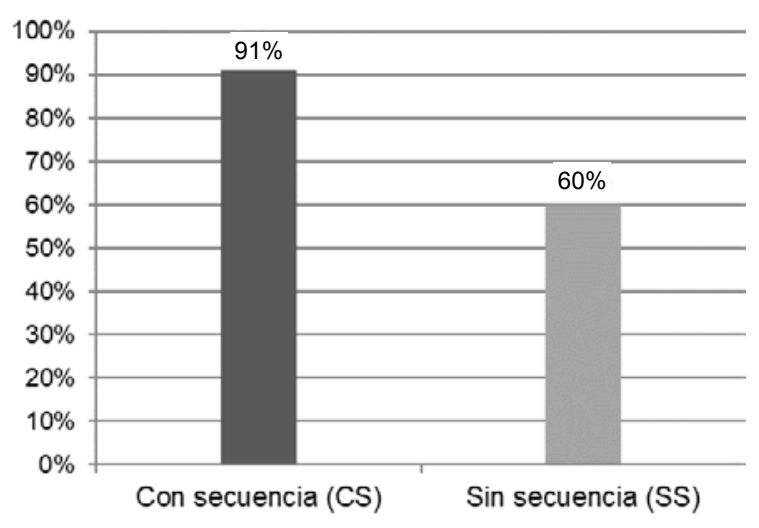

Figura 1. Porcentaje de ejecuciones correctas por condición

En cuanto al desempeño individual, con base en el criterio de sujeto exitoso/a (tres subpruebas correctas) encontramos que en la condición CS 11 de los 15 participantes fueron exitosos, obtuvieron la puntuación máxima. En la condición ss, solo tres obtuvieron la puntuación máxima. En concordancia con lo informado en las pruebas de azar y en las diferencias entre condiciones, el desempeño individual muestra que el retiro de la secuencia afecta sensiblemente la comprensión simbólica de imágenes que representan acciones reales en edades tempranas.

\section{Discusión}

La presente investigación tuvo por objetivo indagar por el impacto de la presencia de la secuencia en la comprensión simbólica de imágenes que representan acciones dirigidas hacia un fin por parte de niños y niñas de 30 a 36 meses de edad. Los resultados muestran que los niños y las niñas tienen un desempeño exitoso en la tarea siempre y cuando se les provea la secuencia de la acción en las imágenes. Los resultados muestran que, si bien los niños y las niñas tienen un desempeño 
exitoso en ambas tareas, su ejecución disminuye significativamente si se retira la secuencia de imágenes que representan una acción dirigida hacia un fin. Podría argumentarse que los niños y las niñas responden de esta forma porque tienen una mayor comprensión de secuenciación de eventos y no necesariamente una mayor capacidad de simbolización; sin embargo, si se retira la secuencia se observa que el desempeño decrece. Contar con la secuencia facilita la comprensión simbólica de las imágenes que representan acciones al ofrecer más pistas, por lo que no contar con ella puede implicar una carga cognitiva adicional.

Estos resultados concuerdan con investigaciones que han señalado que a los niños pequeños, e inclusive a los adultos, les resulta más sencillo comprender una acción cuando fluye continuamente (e.g., Newtson \& Enquist, 1976; Zack, 2009). Cualquier interrupción o introducción de pausas artificiales resulta en un procesamiento cognitivo más dificultoso o lento (e.g., Peralta, Gampe \& Daum, 2014; Baldwin et al., 2001; Graf et al., 2007; Spanjers, van Gog \& van Memënboer, 2010). En este sentido, la demanda cognitiva de la tarea ss fue más compleja, ya que los niños y las niñas debían entender que lo que se intentaba representar era una acción y, al mismo tiempo, comprender que esta acción refería un hecho de la realidad. En la condición Cs, los niños y las niñas quizás captaron desde un principio que se trataba de una acción, lo que facilitó relacionar la acción representada en la imagen con la realidad.

Esto último explicaría por qué en el estudio de Harris, Kavanaugh y Dowson (1997) los niños y las niñas mayores de 28 meses escogieron la representación simbólica (imagen) que mostraba el resultado de una acción real, acción que había sido observada en forma completa pero sin mostrar su resultado. En ese estudio las acciones eran desempeñadas por un experimentador en vivo y las secuencias respetaban el flujo natural de las acciones. Además, el procedimiento era inverso al utilizado en la investigación aquí presentada, ya que primero se observaba la acción en vivo y luego se debía seleccionar su resultado en las imágenes.

En la vida cotidiana las acciones no siempre fluyen en forma continua; sin embargo, los y las observadores/as logramos hacer frente a esta complejidad y comprenderlas. En este sentido, futuras investigaciones podrían indagar con mayor profundidad por el impacto de la secuencia en la comprensión simbólica de las imágenes que las representan. Utilizando este mismo diseño resultaría de interés realizar un estudio intrasujetos con medidas repetidas, (ss, CS y viceversa) con el propósito de indagar por el impacto de la secuencia en la ejecución de los mismos participantes. También se podrían utilizar imágenes de video que respeten el flujo natural y completo de las acciones o provocar disrupciones o pausas en momentos preestablecidos o aleatorios. Estas manipulaciones podrían estudiarse evolutivamente y ampliando la muestra de modo que resulte más representativa, con el objetivo de indagar en forma más precisa por el impacto de la presencia de la secuencia en la comprensión simbólica de imágenes que representan acciones reales de acuerdo con la edad.

Consideramos que el estudio aquí presentado se ubica en un área escasamente investigada y aporta información tanto sobre la comprensión simbólica temprana de imágenes que representan acciones reales, como de factores que pueden obstaculizar o facilitar este proceso.

\section{Referencias}

Baldwin, D., Andersson, A., Saffran, J., \& Meyer, M. (2008). Segmenting dynamic human action via statistical structure. Cognition, 106(3), 1382-1407. https://doi.org/10.1016/j.cognition.2007.07.005

Baldwin, D., Baird, J., Saylor, M., \& Clark, A. (2001). Infants parse dynamic human action. Child Development, 72(3), 708-717. https:// doi.org/10.1111/1467-8624.00310 
DeLoache, J. S. (1987). Rapid change in the symbolic functioning of very young children. Science, 238(4833), 1556-1557. https://doi.org/10.1126/ science. 2446392

DeLoache, J. S. (2004). Becoming symbol-minded. Trends in Cognitive Sciences, 8(2) 66-70. https:// doi.org/10.1016/j.tics.2003.12.004

Graf, M., Reitzner, B., Corves, C., Casile, A., Giese, M. A., \& Prinz, W. (2007). Predicting pointlight actions in real-time. NeuroImage, 36 , T22-T32. https://doi.org/10.1016/j.neuroimage.2007.03.017

Harris, P. L., Kavanaugh, R. D., \& Dowson, L. (1997). The depiction of imaginary transformations: Early comprehension of a symbolic function. Cognitive Development, 12(1), 1-19. https://doi. org/10.1016/S0885-2014(97)90028-9

Ittelson, W. H. (1996). Visual perception of markings. Psychonomic Bulletin \& Review, 3(2), 171-187. https://doi.org/10.3758/BF03212416

Jauck, D. E., \& Peralta, O. A. (2017). La comprensión simbólica de imágenes digitales que represen$\tan$ acciones dirigidas hacia un fin. Avances en Psicología Latinoamericana, 35(3), 601-614. https://doi.org/10.12804/revistas.urosario.edu. co/apl/a.5070

Jauck, D. E., \& Peralta, O. A. (2019). Two-year-olds' symbolic use of images provided by a tablet: A transfer study. Frontiers in Psychology, 10, 2891. https://doi.org/ 3389/fpsyg.2019.02891

Newtson, D., \& Engquist, G. (1976). The perceptual organization of ongoing behavior. Journal of Experimental Social Psychology, 12(5):436-450. https://doi.org/10.1016/0022-1031(76)90076-7

Peralta, O. A, Gaump, A., \& Daum, M. (2014). The development of action perception: Predicting action goals from static images in real time. Unpublished manuscript.

Raynaudo, G., Sartori, M., \& Peralta, O. (2017). Tecnologías en los hogares y su uso por parte de niños (0-8 años) en Argentina. XXXVI Congreso Interamericano de Psicología. Mérida. Trabajo completo publicado en actas.
Rideout, V. (2017). The common sense census: Media use by kids'age zero to eight. Common Sense Media. Rideout, V., \& Hamel, E. (2006). The media family: Electronic media in the lives of infants, toddlers, preschoolers, and their parents. Kaiser Family Foundation.

Saylor, M. M., Baldwin, D. A., Baird, J. A., \& LaBounty, J. (2007). Infants' on-line segmentation of dynamic human action. Journal of Cognition and Development, 8(1), 113-128. https://doi.org/10.1080/15248370709336996

Sheehan, K. J., \& Uttal, D. H. (2016) Children's learning from touch screens: A dual representation perspective. Frontiers in Psychology, 7:1220. https://doi.org/10.3389/fpsyg.2016.01220

Sigel, I. E. (1978). The development of pictorial comprehension. En B.S. Randhawa \& W.E. Coffman (Eds.), Visual learning, thinking, and communication (pp. 93-1 11). Academic Press.

Spanjers, I. A., van Gog, T., \& van Merriënboer, J. J. (2010). A theoretical analysis of how segmentation of dynamic visualizations optimizes students' learning. Educational Psychology Review, 22(4), 411-423. https://doi.org/10.1007/ s10648-010-9135-6

Troseth, G. L. (2003). TV guide: Two-year-old children learn to use video as a source of information. Developmental Psychology, 39(1), 140-150. https:// doi.org/10.1037/0012-1649.39.1.140

Vittrup, B, Snider, S., Rose, K., \& Rippy, J. (2016). Parental perceptions of the role of media and technology in their young children's lives. Journal of Early Childhood Research, 14(1), 43-54. https://doi.org/10.1177/1476718X14523749

Waismana, I., Hidalgoa, E., \& Rossia, M. L. (2018). Uso de pantallas en niños pequeños en una ciudad de Argentina. Archivos Argentinos de Pediatría, 116(2), 186-195. https://doi.org/10.5546/ aap.2018.e186

Woodward, A. L. (1998). Infants selectively encode the goal object of an actor's reach. Cognition, 69(1), 1-34. https://doi.org/10.1016/S00100277(98)00058-4 
Woodward, A. L., \& Gerson, S. A. (2014). Mirroring and the development of action understanding. Phil. Trans. R. Soc. B.: Biological Sciences, 369(1644):20130181. https://doi.org/10.1098/ rstb.2013.0181
Zack, E., Barr, R., Gerhardstein, P., Dickerson, K., \& Meltzoff,A. N. (2009). Infant imitation from television using novel touch-screen technology. British Journal of Development Psychology, 27(1), 1326. https://doi.org/10.1348/026151008X334700

Recibido: agosto 21, 2019

Aprobado: junio 3, 2020 